\title{
Abstract
}

Children in residential care tend to be less content with quality of care arrangements and participation opportunities compared to children in foster care. Using quantitative methods this study did explore if social workers differ in their views in child participation and service quality. We compared responses from social workers who are responsible for (1) planning in residential care or (2) planning in foster care. Analyses focus on whether possible differences may be explained by collaboration between professionals and social workers work engagement.

We found that social workers from residential care services seem more prudent in letting children participate in case planning compared to social workers planning for foster care.. Social workers judgments of service quality were also highly affected by their organizational affiliation but personal factors such as work engagement may also play a part. The differences we found regarding social workers attitudes towards participation and their rating of service quality are associated with organizational culture. Understanding how organizations shape social workers decisions to include or exclude children in care planning may help gain a more comprehensive understanding of what is needed to take the participation agenda forward.

Key words: participation, decision-making, child protection, planning, engagement, organization

This is the peer reviewed version of the following article: Organizational factors and child participation in decisionmaking: differences between two child welfare organizations, which has been published in final form at http://doi.org/10.1111/cfs.12076. This article may be used for non-commercial purposes in accordance with Wiley Terms and Conditions for Self-Archiving. 
Introduction

Child participation is identified as a key area in which current practices do not seem to meet the expectations set forth in current Norwegian child protection policy (BR 2011). Prevalence of child participation is uncertain because most studies are either small scale or situated in a specific context. In Norway Oppedal (1999) reported that in cases where children had been given care orders $(\mathrm{N}=297)$ children's views were represented in $21 \%$ of the cases in the age group of 7-11 year olds and in about $52 \%$ for older children. In the UK Thomas and O'Kane (1999) found that about half of the children attended review meetings, but that "levels of participation and degrees of engagement were dependent on a range of contextual factors, particularly the age of the child, the context of decision making and the attitudes of adults involved". Later, Timms and Thoburn (2003) found that about $35 \%$ of children in the UK had "co-authored" their care plan. Landsdown (2010) identified consultative participation as prominent in child protection investigations and judicial administrative proceedings in UK. This means that although children may be asked what they think, their role as active participants often are sustained in cases when there are adults to facilitate the process. This becomes particularly evident in child protection where the agenda is set by social workers.

The UNCRC has been a catalyst for research about how child participation is being implemented within social services. Although the convention enjoys widespread support for the rights claims embodied in it, tension still remains as to the relative importance and merit of child participation when it is considered being in conflict with protection of the child. This is sometimes the case within family law (James et al 2010). In a review of the development of research in England and Wales in planning and reviewing for children in care, Thomas (2011) reported that research on child participation dates back about fifteen years and that new research is overdue. He concludes that "if nothing else, it would be useful to know whether patterns of participation have changed as a result of the investment by many organisations, including government, in training, guidance and toolkits" (Thomas 2011, p.396). Factors such as organizational culture and climate may be of importance when determining the quality of the child welfare services (Glisson and Green 2011), and for successful adoption of new practices in social work (Hemmelgarn et al 2006).

\section{Predictors of child participation}


In a study set out to evaluate participation among 7 to 12 year olds, Vis and Thomas (2009) found that there was a tendency for older children to more often be included. Age may play a part in how participation is attempted as well as in what can be achieved. The results from studies on social workers views on child participation do however point to different explanations than children's' abilities for children not participating. The attitudes, knowledge and skills among social workers are among these.

\section{Social worker attitudes}

A number of studies have been carried out looking at child, parent or case characteristics being factors influencing social workers' decisions to remove a child, (see Arad-Davidzon and Benbenishty 2008). Studies focusing on the personal characteristics of social workers who make these decisions are however quite rare. In a study among licensed child protection workers in Israel, Arad-Davidzon and Benbenishty (ibid) used vignettes to study workers' decision making attitudes towards removal or reunification. They found that the workers' attitudes towards issues in child protection such as removal, reunification, duration of alternative care, and perceived quality of out of home placements, were key determinants for their recommendations. The wishes of children and parents had no significant affect upon that matter. This means that social workers tend to first decide, using their professional judgement, what they think is the best for the child based upon the facts of the case. The views of children and parents seem likely to be ignored if they do not correspond with the social workers professional judgements.

A study by Vis et al (2012) investigated priorities and attitudes towards child participation among case managers. The purpose was to explore possible obstacles towards achieving child participation. In a questionnaire containing twenty statements about child participation, groups of case managers $(\mathrm{N}=54)$ and social work students $(\mathrm{N}=32)$ were asked to rate their level of agreement with these. The results suggested three main reasons for children not being allowed to participate: communication difficulties; because child participation was not deemed necessary; or that participation was considered inappropriate because it might be harmful. The authors suggested that case managers might find it difficult to facilitate participation due to organizational barriers. Additionally the study observed a loss of enthusiasm for facilitating participation among experienced social workers compared to social work students and less experienced professionals.

\section{Organisational factors}


Several studies point to the decision-making processes itself as an obstacle. Children will be more likely to opt out if the process involves attending very formal meetings (Thomas and O'Cane 1999) or if the process is too bureaucratic due to formal procedural regulations (Willumsen and Skivenes, 2005). Leeson (2007) emphasise that processes need to be 'child friendly' in order for children to participate effectively. In a review of possible relationships between participation and outcomes related to psychological health, Vis et al (2011) argue that:

"It is a matter of concern that social workers report that case processing in child protection does not easily allow them to guide a child through the whole process from investigation and assessment to decision-making, implementation and evaluation of services, and that children are being alienated by a system that is not designed for them, and where not being listened to affects their feeling of self- worth" (ibid p. 333).

They argue that additional support and advocacy services may be needed in order for children to form relationships and engage in these processes. In a review of children and families' involvement in social work decision making, Gallagher et al (2012) conclude that effective participation can be impeded "by overly bureaucratic and managerial practice cultures and by a lack of time available to build relationships" (p. 83).

In a review exploring parental engagement in child welfare Kemp et al (2009) pointed out that worker attitudes and behaviours are deeply embedded in and shaped by organizational influences and factors. They do however add that "a growing body of research points to the importance of supportive work environments, worker empowerment, and inclusive worker attitudes in efforts to more effectively engage and serve parents and families" (ibid p. 109). Because positive relationships between workers and clients are most likely to occur in organizations where caseworkers agree on their roles and are satisfied with their jobs, further attention should be given also to organizational factors that may determine quality and level of child participation. The extent of administrative duties and high case loads of statutory child protection workers has been reported being a factor limiting the contact between the social workers and the clients (Darlington et al 2010).

Engaged organizational climates may be characterized by "employee perceptions that they are able to personally accomplish many worthwhile things at work and remain personally involved in their work and concerned about their clients" (Glisson 2011, p. 585). The nature of the responsibilities 
and the problems experienced by the children and families the social workers serve, are factors known to influence work environment and the quality of services social workers provide.

\section{Organizational factors and service quality}

Two separate meta-analyses have examined engagement and its association with treatment outcomes, showing a modest association between the development of a helping relationship and positive treatment outcomes thereby suggesting that client engagement improves treatment outcomes (Shirk \& Karver 2003, Horvath \& Symonds 1991),.

As pointed out in a review of the relationship between child participation and how this affects services and outcomes (Vis et al 2011) suggests that the relationship between child and social workers' is instrumental in keeping children engaged. In residential psychotherapeutic treatment, client engagement is commonly identified as a prerequisite to quality of service delivery (Cunningham et al., 2009, Englebrecht et al., 2008). The relationship between social worker engagement and client engagement does not seem to have been thoroughly evaluated to date. One study did however report a negative correlation between social workers stress and work engagement and a positive correlation between social worker engagement and parents' engagement in child protection (Gladstone et al 2011), suggesting that social workers and clients may promote engagement in one another.

Glisson and Hemmelgarn assessed the effects of increasing cooperation and coordination of services in public children's service agencies. The study concluded that the organizational climate, including cooperation, role clarity, and personalization was the primary predictor of service quality and measured service outcomes such as children's improved psychosocial functioning (Glisson and Hemmelgarn 1998). Martinussen et al (2012) found that collaboration predicts service quality in Norwegian municipal health and social services. Salanova et al (2005) found work engagement to predict service climate and user satisfaction.

In summary there is a growing body of research suggesting a relationship between participation and factors related to organisation and culture within social services. Among these are social workers engagement, work climate, organizational barriers within services and social workers' priorities and attitudes towards children's participation. This study was also motivated by the findings from a Norwegian user survey (BUFDIR 2010, 2011) among children living in care. It was reported that children living in foster care were more likely to agree that they were allowed participation in important decisions affecting themselves $(80 \%, \mathrm{~N}=311)$ compared to children living in residential 
care $(61 \%, \mathrm{~N}=468)$. Children living in foster care were more likely to be happy with their care arrangements (88\%) compared to children in residential care $(65 \%)$.

Planning and follow up for children in foster care and residential care is the responsibility of different social services organizations. In Norway it is the social workers from the municipal first tier level who are responsible for planning and reviewing of services for children in foster care. If the child is in residential care this responsibility lies mainly with the residential care centre. In addition to on-site care staff, residential care centres have affiliated interdisciplinary teams, who assist in the planning process, here referred to as child and family units.

\section{Problems}

The aim of this present study is to assess how social workers from the municipal level and professionals from child and family units view child participation and service quality. Analysis is aimed at exploring if there are any differences between social workers from the two organizations. We use measures of work engagement and collaboration between professionals as indicators of organizational culture and analyze whether this explains any differences in how these to groups of social workers assess service quality and child participation.

\section{Methods}

\section{Participants}

A total of 87 social workers participated, 75 women and 12 men. Mean age was 42.8 years $(\mathrm{sd}=$ 9.1). Most participants had a bachelor's degree in child protection (43) or social work (16). Twenty participants had a different bachelor degree and five did not have an academic degree. Three respondents did not provide this information. The participants had on average 15.3 years $(\mathrm{sd}=9.6)$ work experience. Participants were recruited and data collected in October and November 2011.

Participants were recruited from two different child welfare organisations. The first group consist of 38 social workers from a first tier municipal child and family social services department who were asked to participate while attending a training program in child communication. All the attending social workers agreed to participate and a response rate of $100 \%$ was obtained by having the participants complete the questionnaire on-site. The sample represents about $84 \%$ of the work force in the child welfare services department at that particular municipality. These participants 
were social workers who mainly are responsible for investigating reports of child abuse and neglect as well as planning of services for children living at home or in foster care.

The second group consisted of 49 social workers from eleven different child and family units affiliated with residential care institutions. This group was recruited through the regional residential care administration who asked their employees to participate in an online on-line survey that also included other questions not intended for this study. The response rate was $93 \%$ and the sample represents the entire workforce in child and family units in one administrative region. These social workers are mainly responsible for working with families and municipal services in transitional planning as well as delivery of services while the child is in residential care. We would like to point out that these child and family units are not the workers staffing the residential care institutions.

Participants were informed about the study and consented by answering and returning the questionnaire. Data collection and storage was approved by Norwegian Social Science Data Services.

\section{Measures}

Four different composite measures are used in order to measure (1) social worker view on child participation, (2) social workers view on service quality, (3) collaboration between services and (4) their work engagement. The use of composite measures allows us to calculate a mean score for each respondent and treat this score as a continuous variable. We wanted to include composites that had been used in previous research in order to maximize reliability and provide reference for scores. The collaboration composite was included because one of the most important duties for social workers in our sample is to develop care plans for children and to coordinate in implementation of these plans. Difficulties in cooperation between services at different levels are thus believed to seriously impact how these social workers view child participation and service quality. The work engagement composite was included with reference to the association between social workers' work engagement, treatment outcomes and client engagement that has been located in previous research.

Social workers views on child participation was measured by asking participants to indicate their agreement on five statements that represent some reasons case managers give for not including children in decision-making processes (table 1). This measure was a refined version of a 11 statements index used by Vis et al (2012) which was originally developed to predict the likelihood that social workers will engage children in case processing. Because the 11 statements version had 
unacceptable internal consistency for this present sample, the scale was reduced to five. More specifically we used the principal component method in factor analysis to identify factor loadings and discarded statements with loadings below 0.5 (Costello and Osborne 2005). Participants were asked to indicate agreement or disagreement with each statement on a five-point Likert scale. The Likert scale ranged from 1 'totally disagree' to 5 'totally agree'. A mean score for the scale was calculated. A high mean score does indicate that the social worker see many obstacles towards child participation.

Perceived quality of services was measured using a scale consisting of three statements about user participation, user satisfaction and quality of services. The statements were previously used by Martinussen et al (2012) in order to measure service quality. Participants were asked to respond to statements about quality on a scale ranging from ' $1=$ very bad' to ' $5=$ very good'. See table one for an overview of the composite statements and mean scores and the belonging sd.

Collaboration was measured with eight statements developed by Martinussen et al (2012).

Participants were asked to respond to different statements about cooperation within and between services on a scale ranging from ' $1=$ not at all' to ' $5=$ to a very large degree'. A higher score on the collaboration index indicate the respondents view cooperation as better compared to a low score. Mean scores and the belonging sd were calculated and presented in table 1.

The Utrecht Work Engagement Scale-short (UWES-9) (Nerstad, Richardsen, \& Martinussen, 2010; Schaufeli, Bakker, \& Salanova, 2006) was used to assess work engagement. The UWES-9 consists of nine statements such as "At my work, I feel bursting with energy" and "My job inspires me". The statements are rated on a seven-point scale ranging from ' $1=$ never' to ' $7=$ =always'. Only totale scores were used, not the sub scales. The psychometric properties for this scale is well documented (Mills et al 2012). We used the Norwegian version. The English version is easily available on-line and therefore not reproduced in full here.

--Table 1 about here

Internal reliability for the composite measures were tested and Chronbach'a alpha were .66 for the participation composite, .65 for the quality composite, .68 for the collaboration composite and .87 for UWES- 9 . 
Chi-square $\left(\chi^{2}\right)$ and $t$-test were conducted to test for demographic differences between the respondents. Correlations between demographics, groups and test variables were computed. Oneway ANOVAs were used to explore for differences between groups in attitudes towards child participation, work engagement, collaboration and user orientation.

Prediction of service quality and participation obstacles were examined in two separate hierarchical regression analysis including three blocks of independent variables: first age and gender as control variables, then group membership (municipal vs residential care affiliation), and finally the scaled social-worker appraisals (work engagement and cooperation). In addition service quality was included in the participation obstacles model and vice versa.

\section{Results}

The sample $(\mathrm{N}=87)$ consisted of 49 welfare officers from family services units at eleven different residential care institutions and 38 social workers from a municipal child and family social services department. Respondents were predominantly women $(87 \%, \mathrm{~N}=75)$ but there was no significant gender difference between the groups $\left(\chi^{2}=1.97, \mathrm{df}(1)\right)$. Social workers from both groups were experienced and had a median of seven years employment with current organization and a median of 13 year work experience in total. Although required formal qualifications are at about the same academic level for both groups there were some differences in type of education. The child and family care units were more interdisciplinary with $35 \%$ of employees holding a primary degree other than social work compared to $24 \%$ in the municipal group. We think this may be explained by the fact that the child and family units are meant to be more focused towards providing therapy and consultations compared to the emphasis in municipal child protection on investigations and prevention. Social workers from the child and family units were on average older $(M=44.8$, $\mathrm{SD}=8.99)$ compared to the municipal group $(\mathrm{M}=40.5, \mathrm{SD}=8.84)$. Although statistically significant $(t=2.20, \mathrm{df}(80), \mathrm{p}<0.05)$ we consider an age difference of four years to be of little practical significance taking into account that there was no between groups difference with respect to years of education or years of social work experience.

Descriptive statistics, including correlations between variables, are presented in table one. Age was negatively related to collaboration $(\mathrm{r}=-.26)$ indicating that younger social workers find cooperation in and between services more difficult than their older colleagues. Age was also related to participation attitudes $(\mathrm{r}=.24)$ thus older social workers were more likely to agree with statements that represent reasons for choosing not to engage children in decision-making processes. Although age was strongly related to total number of years work experience $(\mathrm{r}=.78)$ there was no relationships between age and work experience in current position. When controlling for total years of work 
experience, by calculating partial correlations, age was still related $(\mathrm{r}=.24)$ with participation obstacles but not with collaboration. Quality of services was strongly related to organizational affiliation $(\mathrm{r}=.48)$ and unrelated to other variables. Group adherence, i.e. municipal or residential care affiliation, was related to participation obstacles $(\mathrm{r}=.39)$, user orientation $(\mathrm{r}=.48)$ and collaboration $(\mathrm{r}=-.29)$. Engagement was not related to any other variable.

\section{---Table 2 about here}

With respect to participation obstacles, collaboration and user orientation (table 3), we found a difference between municipal child protection affiliated social workers and social workers from the child and family units.. Interpreted as 'common language effect sizes' (McGraw and Wong 1992) we found that social workers from the municipal group had about $71 \%$ chance of scoring higher on cooperation than a social worker from the residential group. Residential care affiliated workers on the other hand had about $74 \%$ and $80 \%$ chance respectively, for scoring higher on obstacle towards participation and service quality. This means that although social workers in the residential care group see more obstacles towards achieving participation they are none the less more likely to think that quality of services are good.

-- table 3 about here

The results of two separate hierarchical regression analysis that was used for testing what may predict (1) participation obstacles and (2) social workers rating of services quality are displayed in table 4. Demographics explained a small and non-significant part of the variation. The most important variable for predicting both participation obstacles and quality was municipal versus residential care group adherence. This explained $18 \%$ of variance in quality and $13 \%$ of the variation in participation obstacles.

-- table 4 about here

In summary, we found that social workers from two different branches of the child welfare organization differ in the way they view child participation, service quality and collaboration. Social workers from second tier, the child and family units, see participation as more difficult than those working in first tier municipal child protection. This is also true when controlling for sex, age and work experience. Work engagement and professionals collaboration does not contribute additionally to prediction of participation when organizational affiliation is controlled for. Service 
quality is rated higher by social workers from second tier compared to social workers in the field, controlling for age sex and experience. There is an indication that work engagement is not embedded in organizational culture, and that it may impact upon social workers judgments of service quality.

\section{Discussion}

Our finding does to some degree correspond with the findings in a study conducted by the Norwegian Directorate for Children, Youth and Family Affairs (BUFDIR 2010,2011). In this study it was reported higher satisfaction with regards to participation opportunities among children living in foster care, for which follow up is the responsibility of municipal child and family services, compared to children living in residential care.

One explanation may be that there are differences between children in residential care and in foster care with respect to their abilities and severity of social problems. Children with severe behavioral or social problems are in general likely to be admitted to residential care rather than foster care. Establishing trust and building partnerships with children with severe social problems may indeed be more difficult. Even if it has been agued that the view of children in society is changing towards a greater appreciation of children's capacities (Mayall, 2002) and that we should view children as human ' beings' rather than 'becomings' (Lee, 2001) it seems that children's perceived capacities still do determine what opportunities they get with respect to participation in the processing of their case. These findings may therefore not only reflect differences in priority and culture but may also be explained by de facto differences between children living in different forms of care. In the US Keller et al (2010) found higher prevalence of mental health and substance use problems among children in residential care compared to foster care. We are not aware of any study profiling Norwegian children living in care, in a comparable manner, but would expect that similar differences exist because certain forms of residential care is intended for children with more serious problems. Additionally may rules and routines associated with living in residential care be more set and less open for negotiation and individual adaptations when compared to living in a foster family. We are therefore not prepared to conclude that participation in residential care is comparably low solely because of social worker attitudes.

Difficult children also have the right to participate in decision-making. Children and adolescents admitted to residential care may indeed find themselves in an even more vulnerable situation 
compared to children who are looked after at home or placed in foster care. The limited impact legislation seem to have had in influencing/ altering social work practice with regards to child participation is perhaps not a specific Norwegian problem, indeed much the same observation was made by Kerr (2006) in Northern Ireland, with respect to the longer term effects of the Children's order of 1996. She concluded that one also need resources to change the culture and attitudes of those working with children in order to achieve permanent change. It is our belief that leaders and policy-makers should address differences in culture and decision-making practices in CPS with clearer standards and regulations about when and how children are to be involved in care planning.

As noted by Kemp et al (2009) the degree to which social workers find child participation difficult to promote may vary depending on context and work experience. It should be noted though that they focused on parents engagement, not children's. We included work collaboration within and between social services as an organizational factor to be considered and found a rather large between group effect size in this study. On average the residential care group did find collaboration more problematic. We do think that difference in profiles for clients being served by these to organizations may play a part in this. Child and family units at residential care centres work predominantly with families who are involuntary clients whereas in Norway, municipal social work also includes the provision of voluntary welfare services.

In their review Kemp et al (2009) argued that user engagement was more likely in organisations where caseworkers agree on their roles and cooperate with each other. Thus should more problems with collaboration in residential care correlate with higher participation obstacles scores. There was a small negative correlation $(\mathrm{r}=-.19)$ between these two factors, which might support that hypothesis, but this study did not have enough statistical power to conclude that the relationship should be expected in a different sample. Furthermore did the regression analysis indicate that this relationship may be confounded by the group variable. We have to conclude that although there are theoretical reasons to believe that better collaboration between professionals may help promote user participation we were unable to find evidence of this.

The results concerning work engagement do suggest that there is a high degree of work engagement among the social workers. The scores were close to the 75 percentile of the international norms and barely within the score range classified as 'high' (Schaufeli and Bakker 2003). We did not find any difference between the two groups in our sample. This is of particular interest because work engagement is the only included measure in this study that does seem to be totally independent of group adherence. It should thus be viewed as an individual trait not influenced by organization 
factors. Prior research did support the notion that work engagement promotes user engagement (Gladstone et al 2011), which in turn affects quality of services (Shirk \& Karver 2003, Horvath \& Symonds 1991).Although work engagement did explain about five percent of the variation in social workers quality assessments, as indicated by the regression analysis, we consider these findings inconclusive as to the impact of work engagement upon social workers assessment of service quality. The sample in this study was to small given the low variation in individuals' engagement scores for us to emphasize this finding.

It does seem as if factors relating to organization and type of services offered are the most important predictor of how social workers view potential obstacles towards engaging children in participation practices. The participation obstacles measure may thus primarily inform us about the amount of difficulties associated with participation in different contexts, rather than privately held beliefs and attitudes. This means that even though there seem to be differences in the importance and priority that individual social workers put on child participation, these may be rooted in recognition of what possibilities and limitations there are for participation in different questions and settings. A previous study in which the obstacles measure was used (Vis et al 2012) found that social workers see more obstacles towards participation compared to social work students and that more experienced social workers find participation even more difficult. Our finding that participation obstacles correlate with age and overall work experience in social work do correspond with this, even though organizational affiliation was more important in this sample. It is possible that these findings illustrate how most social workers may think participation is a good idea but that in working with individual cases they develop a more realistic view of what can be achieved by participation within the existing system. This seem to result in participation in practice being assigned a lower priority than social workers ideally think it should be and that this may be ascribed to factors such as resources, organisation and legal framework requirements in case processing.

\section{Limitations}

A sample size of 87 only allows for large differences between groups to be significant in statistical analysis. Thus we acknowledge the risk that true relationships may exist between variables, which we were not able to confirm. This study is totally based on social workers self-reports. Due to this we do not have information about the amount of cases or decisions where the social workers actually facilitate child participation. Future studies should gather information from multiple informants including the child, in order to better establish what relationships exit between successful participation and factors relating to social-worker and organizational factors. We would also add that because three of our scaled composite measures had questionable (Gorge and Mallery 
2003) internal consistency with Chronbach's alpha $<7$, further refinement of statements included in these composite measures should be undertaken if they are to be used in future studies.

\section{Conclusion}

The results in this study point to decision making contexts and organizational culture, collaboration between professionals in particular, being more important than factors relating to individual social workers beliefs and priorities, in determining what opportunities children get to participate. Social workers judgement of service quality is also highly affected by their organizational affiliation but work engagement may be an additional indicator.

Although we do believe that differences in attitudes towards participation is reflected in different practices working with children in foster care and residential care, we cannot conclude which one causes the other. Because attitudes among social workers towards participation seem to be embedded in organizations they may reflect differences in the amount and type of problems children they are planning for is faced with, as well as what sort of services they are planning for.

Future research should perhaps also look at what sort of decisions children do and do not participate in for us to better understand what makes participation more difficult in the residential care setting.

\section{References}

Alderson, P. (2010) Younger children's individual participation in 'all matters affecting the child'. In Percy-Smith, B., Thomas, N (eds) : A handbook of children and young people's participation. Kindle for I Pad version. Retrieved from Amazon.com.

Arad-Davidzon, B. \& Benbenishty, R. (2008.). The role of workers' attitudes and parent and child wishes in child protection workers' assessments and recommendation regarding removal and reunification. Children and Youth Services Review. 30,107 - 121

BUFDIR (2010) Barne, Ungdoms og Familiedirektoratet. Brukerundersøkelse blandt barn $i$ statlige og private barneverntiltak. Rambøll: Oslo

BUFDIR (2011) Barne, Ungdoms og Familiedirektoratet. Brukerundersøkelse. Barn i statlige og private barneverntiltak. Rambøll: Oslo

BR (2011) Barnevernpanelets Rapport (Report from the child welfare comission). Retrieved on september 20, 2012 from:

http://www.regjeringen.no/upload/BLD/Barnevern/2011/barnevernpanelets_rapport.pdf

Cohen, J. (1969) Statistical Power Analysis for the Behavioral Sciences. Academic Press:NY 
Costello, A. B. \& Osborne, J. W. (2005). Best practices in exploratory factor analysis: Four recommendations for getting the most from your analysis. Practical Assessment, Research \& Evaluation, 10, 1-9.

Cunningham, W., Duffee, D. E., Huang, Y., Steinke, C. M., \& Naccarato, T. (2009). On the meaning and measurement of engagement in youth residential treatment centers. Research on Social Work Practice 19, 63-76. DOI: 10.1177/1049731508314505

Darlington, Y., Healy, K., \& Feeney, J. A. (2010). Challenges in implementing participatory practice in child protection: A contingency approach. Children and Youth Services Review, 32, $1020-1027$.

Englebrecht, C., Peterson, D., Scherer, A., \& Naccarato, T. (2008). "It's not my fault": Acceptance of responsibility as a component of engagement in juvenile residential treatment. Children and Youth Services Review, 30, 315-327

Gallagher, M., Smith, M., Hardy, M., \& Wilkinson, H. (2012). Children and families' involvement in social work decision making. Children \& Society, 26(1), 74-85.

George, D., \& Mallery, P. (2003). SPSS for Windows step by step: A simple guide andreference. 11.0 update (4th ed.). Boston: Allyn \& Bacon.

Gladstone, J., Dumbrill, G., Leslie, B., Koster, A., Young, M., \& Ismaila, A. (2011). Looking at engagement and outcome from the perspectives of child protection workers and parents. Children and Youth Services Review. doi:10.1016/j.childyouth.2011.09.003

Glisson, C., Hemmelgarn, A. (1998). The effects of organizational climate and interorganizational coordination on the quality and outcomes of children's service systems, Child Abuse \& Neglect, 22, $401-421$.

Glisson, C., Green, P. (2011). Organizational climate, services, and outcomes in child welfare systems, Child Abuse \& Neglect 35, 582 - 591.

Hemmelgarn, A. L., Glisson, C., \& James, L. R. (2006). Organizational culture and climate: Implications for services and interventions research. Clinical Psychology: Science and Practice, 13, 73-89.

Horvath, A. O., \& Symonds, B. D. (1991). Relation between working alliance and out-come in psychotherapy: A meta-analysis. Journal of Counseling Psychology, 38, 139-149.

James, A. L., Haugen, G. M. D., Rantalaiho, M., and Marples, R. (2010). The voice of the child in family mediation: Norway and England. The International Journal of Children' S Rights, 18, 313333.

Kemp,S.P., Marcenko, M.O., Hoagwood,M., and Vesneski, W. (2009) Engaging parents in child welfare services: Bridging family needs and child welfare mandates. Child Welfare. 88, 101-126

Kerr, L. (2006). Children's order 10 years on. Child Care in Practice, 12, 179-183.

Landsdown, G. (2010) The realisation of children's participation rights: critical reflections. In Percy-Smith, B., Thomas, N (eds) : A handbook of children and young people's participation. Kindle for IPad version. Retrieved from Amazon.com. 
Lee, N. (2001). Childhood and society. Open Universuity Press: Buckingham

Leeson, C. (2007) My life in care: Experiences of non- participation in decision-making processes. Child \& Family Social Work 12, 268-277.

Mayall, B. (2002). Towards a sociology for childhood: Thinking from children's lives. Open University Press, Buckingham

Martinussen, M., Adolfsen, F., Lauritzen, C., \& Richardsen, A. M. (2012). Improving interprofessional collaboration in a community setting: Relationships with burnout, engagement and service quality. Journal of Interprofessional Care. Early Online: 1-7, DOI:

$10.3109 / 13561820.2011 .647125$

McGraw, K.O. and Wong, S.P. (1992) 'A Common Language Effect Size Statistic'. Psychological Bulletin, 111, 361-365.

Mills, M.J., Culbertson, S. S., Fullagar C.J. (2012) Conceptualizing and Measuring Engagement: An Analysis of the Utrecht Work Engagement Scale. Journal of Happiness Studies. 13, 519-545

Nerstad, C. G. L., Richardsen, A. M., \& Martinussen, M. (2010). Factorial validity of the utrecht work engagement scale (UWES) across occupational groups in Norway. Scandinavian Journal of Psychology, 51, 326-333.

Oppedal, M. (1999). Rettssikkerhet ved akutte vedtak etter barnevernloven. Universitetsforlaget. Oslo

Salanova, M., Agut, S. and Peiró, J.M. (2005) Linking organizational resources and work engagement to employee performance and customer loyalty: the mediation of service climate, Journal of Applied Psychology 90, 1217-27

Schaufeli, W. B., Bakker, A. B., \& Salanova, M. (2006). The measurement of work engagement with a short questionnaire. Educational and Psychological Measurement, 66, 701-716.

Schaufeli, W., Bakker, A. (2003) Utrecht work engagement scale Preliminary Manual[Version 1, November 2003]. Retrieved on 20.02.2012 at: http://www.beanmanaged.eu/pdf/articles/arnoldbakker/article_arnold_bakker_87.pdf

Shirk, S. R., \& Karver, M. (2003). Prediction of treatment outcome from relationship variables in child and adolescent therapy: A meta-analytic review. Journal of Consulting and Clinical Psychology, 71, 452-464.

Thomas, N. and O'Cane C. (1999). Children's participation in reviews and planning meetings when they are'looked after'in middle childhood. Child \& Family Social Work, 4, 221-230.

Thomas, N. (2011). Care planning and review for looked after children: Fifteen years of slow progress? British Journal of Social Work, 41, 387-398.

Timms, J. and Thoburn, J. (2003) Your shout! A survey of the views of 706 children and young people in public care, London, NSPCC.

UN (1989) United Nations Convention on the Rights of the Child United Nations. http://www.dcsf.gov.uk/everychildmatters/ download/?id=3265 [8 July 2010]. 
Vis, SA, \& Thomas, N. (2009). Beyond talking-children's participation in norwegian care and protection cases. European Journal of Social Work, 12, 155-168.

Vis, S. A., Strandbu, A., Holtan, A. \& Thomas, N. (2011) Participation and health - a research review of child participation in planning and decision-making. Child \& Family Social Work, 16, 325-335

Vis, S. A., Holtan, A. \& Thomas, N. (2012) Obstacles for child participation in care and protection cases - why Norwegian social workers find it difficult. Child Abuse Review. 21, 7-23. DOI: 10.1002/car.115

Willumsen, E. and Skivenes, M. (2005) Collaboration between service users and professionals: legitimate decisions in child protection -- a Norwegian model. Child \& Family Social Work, 10, 197-206. 
Table 1: Components and internal consistency of scales used in the study

\begin{tabular}{ll}
\hline Scale & Statements \\
\hline $\begin{array}{l}\text { Participation } \\
\text { composite }\end{array}$ & $\begin{array}{l}\text { 1. It is important to know as much as possible about the child } \\
\text { before the first consultation }\end{array}$ \\
& 2. Talking about their problems is an additional burden for \\
children & 3. It is easier for children to say what they really mean if they \\
know you well & 4. Special skills are needed in order to talk to children about \\
how they are doing & 5.Children normally don't like to consult with their case \\
manager
\end{tabular}

Mean (sd)

Service quality

composite

1. The opportunities children get to participate in planning of our services are:

2. I think users of our services rate these as:

$3.8(0.7)$

3. I think the quality of our services are:

$4.0(0.5)$

Collaboration composite

1. It is easy to obtain help from other services

2. Service providers often waive their responsibility

3. Systems for inter professional cooperation is missing

$3.0(0.8)$

4. There is agreement between services about the nature of

$3.2(0.7)$ problems and what needs to be done

5. One service provider does not what the others are doing

$3.0(0.8)$

6. Cooperation is difficult due to funding problems

$3.0(1.0)$

7. Services have sufficient knowledge of each others capabilities $2.9(0.7)$

8. Cooperation between services is characterized by mutual

$3.8(0.5)$ respect 
Table 2: Means, standard deviations and bivariate correlations for variables in the study $(\mathrm{N}=82-87)$

\begin{tabular}{|c|c|c|c|c|c|c|c|c|c|}
\hline Variables & $\mathbf{M}$ & SD & 1 & 2 & 3 & 4 & 5 & 6 & 7 \\
\hline \multicolumn{10}{|l|}{ Demograpics } \\
\hline 1.Age & 42.8 & 9.1 & & & & & & & \\
\hline 2. Years experience ${ }^{c}$ & 8.56 & 9.5 & .22 & & & & & & \\
\hline 3.Gender ${ }^{\mathrm{a}}$ & & & $-.25^{*}$ & -.12 & & & & & \\
\hline \multicolumn{10}{|l|}{ Group $^{b}$} \\
\hline 4.Municipal vs residential & & & $.24^{*}$ & .10 & -.15 & & & & \\
\hline \multicolumn{10}{|l|}{ Composite measures } \\
\hline 5.Participation obstacles & 2.87 & .74 & $.24 *$ & .12 & -.15 & $.39 * * *$ & & & \\
\hline 6.Engagement & 4.72 & .92 & -.12 & -.05 & -.02 & -.05 & .01 & & \\
\hline 7. Service quality & 3.89 & .50 & .16 & .13 & -.18 & $.48 * * *$ & .21 & .20 & \\
\hline 8. Collaboration & 3.17 & .24 & $-.26 *$ & -.15 & -.04 & $-.29 * *$ & -.19 & .10 & -.11 \\
\hline
\end{tabular}

Note: $* \mathrm{p}<0.05 ; * * \mathrm{p}<0.01 ; * * * \mathrm{p}<0.001$ (two-tailed), ${ }^{\mathrm{a}}$ Gender was coded $0=$ male, $1=$ female; ${ }^{\mathrm{b}} 0=$ municipal, $1=$ residential; ${ }^{\mathrm{c}}$ In current organization 
Table 3: Between group differences

\begin{tabular}{llclll} 
& \multicolumn{2}{l}{$\begin{array}{l}\text { Residential care family } \\
\text { units }\end{array}$} & \multicolumn{5}{l}{$\begin{array}{l}\text { Municipal child } \\
\text { protection }\end{array}$} \\
& Mean & $\mathrm{Sd}$ & $\mathrm{M}$ & $\mathrm{Sd}$ & $\mathrm{t}$ \\
\hline Work engagement & 4.7 & .99 & 4.8 & .84 & .43 \\
Participation obstacles & 3.1 & .63 & 2.5 & .74 & $-3.90^{* *}$ \\
Collaboration & 3.1 & .22 & 3.3 & .26 & $2.78^{*}$ \\
Service quality & 4.1 & .48 & 3.6 & .38 & $-5.04^{* *}$ \\
\hline
\end{tabular}

Note: ${ }^{*} \mathrm{p}<0.01,{ }^{*} \mathrm{p}<0.001$ 
Table 4: Hierarchical multiple regression analysis for predicting participation obstacles and perceived service quality

\begin{tabular}{|c|c|c|c|c|}
\hline \multirow[b]{2}{*}{ Variables } & \multicolumn{2}{|c|}{$\begin{array}{l}\text { Dependent: } \\
\text { Participation } \\
\text { obstacles }\end{array}$} & \multicolumn{2}{|c|}{$\begin{array}{l}\text { Dependent: } \\
\text { Service quality }\end{array}$} \\
\hline & $\Delta \mathrm{R}^{2}$ & $\beta$ & $\Delta \mathrm{R}^{2}$ & $\beta$ \\
\hline Step 1:Demograpics & 0.06 & & 0.04 & \\
\hline Age & & 0.01 & & 0.03 \\
\hline $\operatorname{Sex}(0=$ male $)$ & & -0.10 & & -0.13 \\
\hline Step 2: Group & $0.13 * *$ & & $0.18 * * *$ & \\
\hline $\begin{array}{l}0=\text { municipal, } \\
1=\text { residential }\end{array}$ & & $0.54 * *$ & & $0.44 * * *$ \\
\hline $\begin{array}{l}\text { Step 3: Composite } \\
\text { measures }\end{array}$ & 0.00 & & 0.05 & \\
\hline Engagement & & 0.02 & & $0.13 *$ \\
\hline Collaboration & & -0.17 & & -0.04 \\
\hline Service quality & & -0.03 & & N.A \\
\hline $\begin{array}{l}\text { Participation } \\
\text { obstacles }\end{array}$ & & N.A & & -0.01 \\
\hline $\mathrm{R}^{2}$ & $0.20 *$ & & $0.27 * * *$ & \\
\hline
\end{tabular}

Note: ${ }^{*} \mathrm{p}<0.05 ;{ }^{* *} \mathrm{p}<0.01 ; * * * \mathrm{p}<0.001$. All coefficients taken from stage three of the regression 